\title{
Study of Mini Channel Heat Sink with Different Internal Configuration
}

\author{
Muhammad Akif Rahman ${ }^{1, *}$, Md Badrath Tamam ${ }^{2}$, Md Sadman Faruque ${ }^{3}$ and A.K.M. Monjur Morshed ${ }^{4}$ \\ 1,2,3 Department of Mechanical Engineering, Military Institute of Science and Technology, Dhaka, Bangladesh \\ ${ }^{4}$ Department of Mechanical Engineering, Bangladesh University of Engineering and Technology, Dhaka, Bangladesh
}

\begin{abstract}
In this paper a numerical analysis of three-dimensional laminar flow through rectangular channel heat sinks of different geometric configuration is presented and a comparison of thermal performance among the heat sinks is discussed. Liquid water was used as coolant in the aluminum made heat sink with a glass cover above it. The aspect ratio (section height to width) of rectangular channels of the mini-channel heat sink was 0.33 . A heat flux of $20 \mathrm{~W} / \mathrm{cm}^{2}$ was continuously applied at the bottom of the channel with different inlet velocity for Reynold's number ranging from 150 to 1044. Interconnectors and obstacles at different positions and numbers inside the channel were introduced in order to enhance the thermal performance. These modifications cause secondary flow between the parallel channels and the obstacles disrupt the boundary layer formation of the flow inside the channel which leads to the increase in heat transfer rate. Finally, Nusselt number, overall thermal resistance and maximum temperature of the heat sink were calculated to compare the performances of the modified heat sinks with the conventional mini channel heat sink and it was observed that the heat sink with both interconnectors and obstacles enhanced the thermal performance more significantly than other configurations. A maximum of $36 \%$ increase in Nusselt number was observed (for $\mathrm{Re}=1044$ ).
\end{abstract}

\section{Introduction}

With the advancement of technology, the demand for small sized electronic devices is increasing. With the decrease of size, the power dissipation increases as a result requiring more heat transfer rate for heat dissipation [1]. As the traditional heat dissipation methods are not effective enough, there is a growing need for improving the heat transfer capability of heat sinks. The rate of heat flow increases with the decrement of hydraulic diameter, which leads to increasing heat transfer rate [2]. Following this principle micro-channel and mini-channel heat sinks were designed. Hydrothermal properties of mini-channel heat sinks were studied by Ghasemi [3] for different hydraulic diameters. It was found that the heat sink with less hydraulic diameter showed better thermal performance by having less thermal resistance than other heat sinks. An experiment was conducted to study pressure drop of mini-channel heat sink $(\mathrm{D}=2.54 \mathrm{~mm})$ and micro-channel heat sink $(\mathrm{D}=510 \mu \mathrm{m})$ by Bowers [4]. The experimental results showed that, in comparison to micro-channel heat sink, mini-channel heat sink with less pressure drop results in a better performance. According to the study of Lei et al. [5], multilayer heat sinks proved to be better in achieving high heat flux compared to single-layer heat sinks. The multilayer structure having larger surface areas leads to higher heat transfer co-efficient. In another study, to observe the thermal performance of double- layered and single-layered mini-channel heat sink having same dimensions, it was found that double-layered heat sink has better thermal performance than the singlelayered heat sinks [6]. For instance, various research works have been conducted to passively increase the hydrothermal performance of mini-channel and microchannel heat sinks.There are numerous ways of increasing the performance of mini-channel heat sink, such as, modifying geometry, increasing surface area, reducing thermal resistance, disruption of boundary layer formation, secondary flow introduction. Tikadar et al. [7] conducted a three dimensional numerical analysis which was for parallel and counter flow mini-channel heat sinks and observed that, interconnectors have a remarkable impact on the performance of counter flow mini-channel heat sinks, however, when it comes to parallel flow mini-channel heat sink it does not have much significance. To increase the secondary flow through the interconnectors, wall-jets or obstacles can be incorporated. This geometric modification results in higher heat transfer rate by decreasing the thermal resistance inside the channel [8]. Tikadar et al. [9] at his theses took a novel approach by incorporating interconnectors in order to disrupt and redevelop boundary layer inside the channel, which consequently led to improved thermal performance. 
Table 1. Nomenclature

\begin{tabular}{|c|c|c|c|}
\hline $\mathrm{D}_{\mathrm{h}}$ & $\begin{array}{c}\text { hydraulic } \\
\text { diameter (mm) }\end{array}$ & $\mathrm{T}_{\mathrm{w}}$ & $\begin{array}{c}\text { average } \\
\text { temperature } \\
\text { of solid- } \\
\text { liquid } \\
\text { interface (K) }\end{array}$ \\
\hline $\mathrm{P}_{\text {pump }}$ & $\begin{array}{c}\text { pumping } \\
\text { power (watt) }\end{array}$ & Q & $\begin{array}{l}\text { volume flow } \\
\text { rate }\left(\mathrm{m}^{3} / \mathrm{s}\right)\end{array}$ \\
\hline $\mathrm{V}_{\text {in }}$ & $\begin{array}{l}\text { inlet velocity } \\
\qquad(\mathrm{m} / \mathrm{s})\end{array}$ & $\mathrm{q}_{\mathrm{w}}$ & $\begin{array}{l}\text { heat flux at } \\
\text { solid liquid } \\
\text { interface } \\
\left(\mathrm{W} / \mathrm{cm}^{2}\right)\end{array}$ \\
\hline $\mathrm{C}_{\mathrm{p}}$ & $\begin{array}{c}\text { specific heat } \\
(\mathrm{Kj} / \mathrm{KgK})\end{array}$ & $\mathrm{q}^{\mathrm{n}}$ & $\begin{array}{l}\text { applied heat } \\
\text { flux }\left(\mathrm{W} / \mathrm{m}^{2}\right)\end{array}$ \\
\hline $\mathrm{K}_{\mathrm{s}}$ & $\begin{array}{c}\text { thermal } \\
\text { conductivity } \\
(\mathrm{W} / \mathrm{mK})\end{array}$ & $\Delta \mathrm{P}$ & $\begin{array}{l}\text { pressure } \\
\text { difference } \\
\text { (Pa) }\end{array}$ \\
\hline$R_{\text {th }}$ & $\begin{array}{l}\text { overall thermal } \\
\text { resistance } \\
\left(\mathrm{K} / \mathrm{W}^{\mathrm{cm}}{ }^{2}\right)\end{array}$ & Symbols & \\
\hline h & $\begin{array}{c}\text { local heat } \\
\text { transfer co- } \\
\text { efficient } \\
\left(\mathrm{W} / \mathrm{m}^{2} \mathrm{~K}\right)\end{array}$ & in & inlet \\
\hline $\mathrm{Re}$ & $\begin{array}{l}\text { Reynolds } \\
\text { number }\end{array}$ & out & outlet \\
\hline $\mathrm{Nu}$ & $\begin{array}{c}\text { local Nusselt } \\
\text { number }\end{array}$ & $\begin{array}{c}\text { Greek } \\
\text { symbols }\end{array}$ & \\
\hline $\mathrm{T}_{\max }$ & $\begin{array}{l}\text { maximum } \\
\text { temperature of } \\
\text { heat sink }(\mathrm{K})\end{array}$ & $\mu$ & $\begin{array}{l}\text { liquid } \\
\text { dynamic } \\
\text { viscosity } \\
(\mathrm{Kg} / \mathrm{ms})\end{array}$ \\
\hline $\mathrm{T}_{\mathrm{hs}}$ & $\begin{array}{l}\text { temperature at } \\
\text { bottom surface } \\
\text { (K) }\end{array}$ & $\rho$ & $\begin{array}{l}\text { density } \\
\left(\mathrm{Kg} / \mathrm{m}^{3}\right)\end{array}$ \\
\hline
\end{tabular}

Based on the above literature, it can be observed that disrupting the boundary layer formation within the channel is an effective way to enhance the heat transfer rate, which can be applicable in case of mini-channel heat sink. In the study, our approach is to improve the thermal performance by boundary layer development and secondary flow incorporation. Therefore, the aim of the study is to introduce inter-connectors along with the obstacles inside the channel, which can play a key role to enhance the heat transfer rate. Furthermore, the positions and numbers of obstacles have a notable impact on the thermo-hydrodynamic performance and the variation of the width of inter-connectors has an influence on the performance of mini-channel heat sink as well, so two different widths of inter-connectors are considered. In addition, a comparison is done with the modified channels with the conventional one. A three-dimensional model is developed for laminar flow through rectangular channel heat sink with the help of a software ANSYS FLUENT. Finally, the effects of different positions of obstacles and various widths of inter-connectors on the parameters, for instance, Nusselt number, overall thermal resistance and maximum temperature are studied.

\section{Methodology}

\subsection{Computational Domain for Channels}

In this experiment a three-dimensional numerical analysis was conducted of five different models of mini channel heat sink. The three-dimensional model of conventional mini channel heat sink is showed in figure 1.

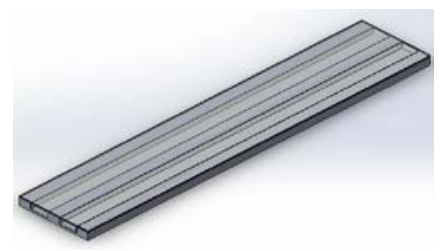

Fig. 1. Conventional mini channel heat sink (3D)

\subsection{Arrangement and Dimensions}

The heat sinks were considered to be made of aluminum. There was a glass cover over the channels. As coolant liquid water was passed through the channels. A consistent heat flux was applied at the bottom surface.

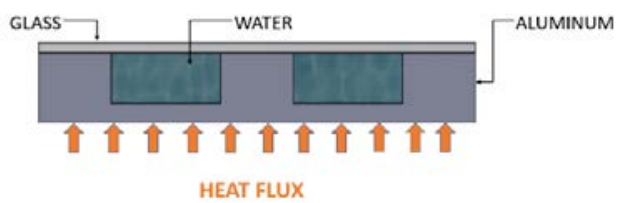

Fig. 2. System arrangement 
Five cases were studied in this experiment.

Table 2. Cases Studied

\begin{tabular}{|c|c|c|}
\hline case 01 & (a) & $\begin{array}{c}\text { Conventional mini } \\
\text { channel heat sink }\end{array}$ \\
\hline case 02 & (b) & $\begin{array}{c}\text { Heat sink with } \\
\text { interconnector of } \\
\text { width } 1 \text { mm }\end{array}$ \\
\hline case 03 & (c) & $\begin{array}{c}\text { Heat sink with } \\
\text { interconnector of } \\
\text { width } 1.5 \text { mm }\end{array}$ \\
\hline case 04 & (d) & $\begin{array}{c}\text { Heat sink with } \\
\text { interconnector and } \\
\text { obstacles (i) }\end{array}$ \\
\hline case 05 & (e) & $\begin{array}{c}\text { Heat sink with } \\
\text { interconnector and } \\
\text { obstacles (ii) }\end{array}$ \\
\hline
\end{tabular}

In order to enhance thermal performance, interconnectors between two rectangular parallel channels and obstacles inside the channels were introduced.

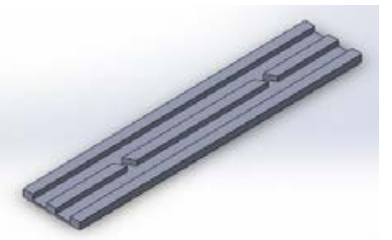

(a)

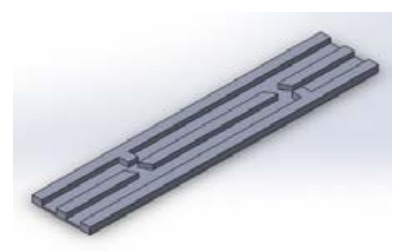

(c)

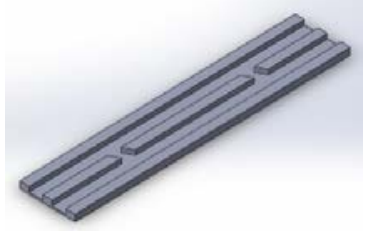

(b)

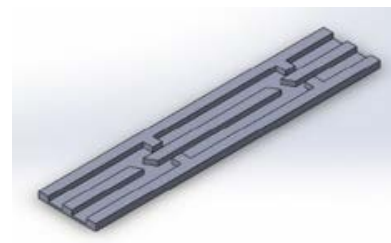

(d)
Fig. 3. Configurations (3D) of modified heat sinks without glass cover for cases $(02,03,04,05)$ respectively
Table 3. Key dimensions of the heat sink

\begin{tabular}{|c|c|}
\hline Channel & $\begin{array}{c}30 \mathrm{~mm} \times 1.5 \mathrm{~mm} \times 0.5 \mathrm{~mm} \text { (length } \times \\
\text { width } \times \text { height })\end{array}$ \\
\hline Cover & $\begin{array}{c}30 \mathrm{~mm} \times 6 \mathrm{~mm} \times 0.1 \mathrm{~mm} \text { (length } \times \text { width } \\
\times \text { height })\end{array}$ \\
\hline Interconnector & $\begin{array}{r}1 \mathrm{~mm}[\text { Fig.3 (a) }] / 1.5 \mathrm{~mm} \text { [Fig.3 }(\mathrm{b})] \times \\
1 \mathrm{~mm} \text { (length } \times \text { height) } \text { placed at an } \\
\text { angle of } 60 \text { degrees }\end{array}$ \\
\hline Obstacle & $\begin{array}{r}1.3 \mathrm{~mm} \times 6 \mathrm{~mm} \times 0.5 \mathrm{~mm} \text { (length } \times \text { width } \\
\times \text { height) }\end{array}$ \\
\hline $\begin{array}{c}\text { Complete heat } \\
\text { sink }\end{array}$ & $\begin{array}{r}30 \mathrm{~mm} \times 6 \mathrm{~mm} \times 0.7 \mathrm{~mm} \text { (length } \times \text { width } \\
\times \text { height })\end{array}$ \\
\hline
\end{tabular}

\subsection{Mathematical Formulations}

For simplified governing equations the flow was considered to be steady, incompressible and laminar, no slip boundary condition was applied at the walls, radiation heat transfer was neglected and the fluid was considered to have constant properties. The governing equation in this case for heat conducting flowing fluid is the Navier-Stokes equation.

Continuity equation:

$$
\frac{\partial}{\partial x_{i}}\left(\rho_{f} u_{i j}\right)=0
$$

Momentum equation:

$$
\frac{\partial}{\partial x_{i}}\left(\rho_{j} u_{i} u_{j}\right)=-\frac{\partial p}{\partial x_{i}}+\frac{\partial}{\partial x_{i}}\left[\mu_{f}\left(\frac{\partial w_{i}}{\partial x_{j}}+\frac{\partial w_{j}}{\partial x_{i}}\right)\right]
$$

Energy equation:

$$
\frac{\partial}{\partial x_{i}}\left(\rho_{f} u_{i} C_{p f} T\right)=\frac{\partial}{\partial x_{i}}\left(k_{f} \frac{\partial T}{\partial X_{i}}\right)
$$

Reynold's number:

Nusselt number:

$$
\operatorname{Re}=\frac{\rho v_{m} D_{h}}{\mu}
$$

$$
\mathrm{Nu}=\frac{\hbar D_{h}}{\mathbb{K}_{f}}
$$

Pumping power:

Overall thermal resistance:

$$
P_{\text {pump }}=Q_{n} \Delta P
$$

$$
R_{t h}=\frac{T_{h x}-T_{i n}}{Q_{m}}
$$

\subsection{Numerical Setup for Simulation}

For general setup pressure based, steady time, absolute velocity formulation was selected. Energy equation was activated and the flow was selected as laminar. Second order upwind equation was selected for pressure, energy and momentum. To get acceptable result residual factor was set to $10^{-6}$. No slip boundary condition is applied on the walls of the channels and except the bottom surface of the heat sink, adiabatic boundary condition is 
applied on all other surfaces. The input data for boundary conditions is provided in Table 4 .

Table 4. Input Data for Boundary Condition

\begin{tabular}{|c|c|}
\hline Inlet velocity, $\mathrm{v}_{\text {in }}$ & $(0.171-1.187) \mathrm{m} / \mathrm{s}$ \\
\hline Inlet temperature, $\mathrm{T}_{\text {in }}$ & $290 \mathrm{~K}$ \\
\hline Outlet pressure, $\mathrm{P}_{\text {out }}$ & Gauge pressure \\
\hline Heat flux, $\mathrm{q}^{\mathrm{n}}$ & $200000 \mathrm{~W} / \mathrm{m}^{2}$ \\
\hline
\end{tabular}

\subsection{Mesh Independence Test}

Mesh independence test was performed on the traditional mini channel heat sink for $\mathrm{Re}=448$. Three diverse mesh were generated and the results were analyzed with mesh (I) considered as the baseline. Table 5 shows the friction factor for three different mesh generations.

Table 5. Friction factor for three different mesh

\begin{tabular}{|c|c|c|c|}
\hline No. & $\begin{array}{c}\text { Total } \\
\text { Mesh }\end{array}$ & $\begin{array}{c}\text { Friction } \\
\text { Factor }\end{array}$ & $\begin{array}{c}\text { \% of } \\
\text { deviation } \\
\text { from } \\
\text { baseline }\end{array}$ \\
\hline I & 160308 & 0.1904 & \\
\hline II & 223040 & 0.1915 & .58 \\
\hline III & 311696 & 0.1922 & .95 \\
\hline
\end{tabular}

From Table 5 it is observed that for both mesh (II) and mesh (III) the percentages of deviation for friction factor are less than that for mesh (I). Therefore mesh (ii) was selected for configurations of mini channel heat sink.

\subsection{Model Validation Test}

The validity and accuracy of the model that was developed was tested by observing the comparison between the Nusselt number obtained numerically for conventional parallel flow mini channel heat sink with the experimental outcome of Moraveji et al [10]. The comparison is showed in figure 4.

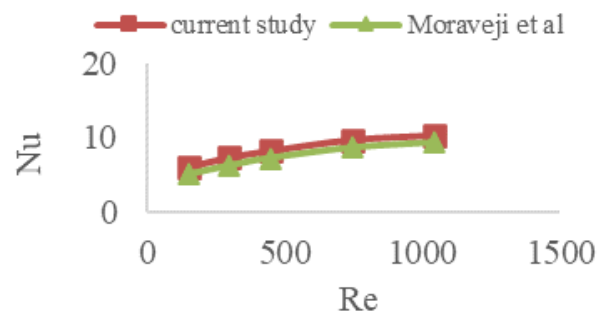

Fig. 4. Comparison between numerical results with experimental outcome of Moraveji et al

\section{Results and Discussion}

The hydraulic and thermal properties can be observed and analyzed by carefully studying the contours found from the simulation process. Velocity and temperature contours of conventional mini-channel heat sink (case 01) for the inlet velocity of $0.51 \mathrm{~m} / \mathrm{s}$ are represented in figure 5 .

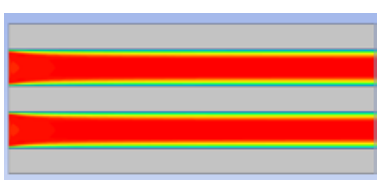

(a)

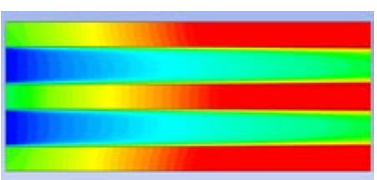

(b)
Fig. 5. (a) velocity contour and (b) temperature contours for case 01

From figure 5 it can be observed that the boundary layer was developed along the length of the channel. The fluid flow became fully developed inside the channel. In the developed region velocity becomes constant. It can be observed from figure 6 that crossing a very short distance the velocity became constant.

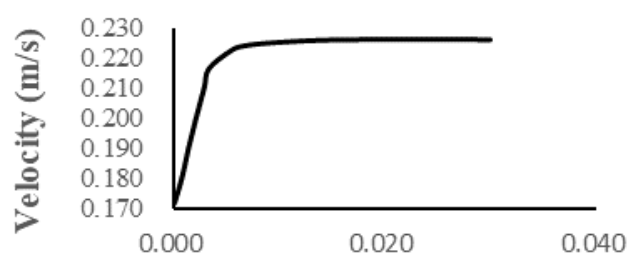

Along the channel length (m)

Fig. 6. Velocity along channel length for case 01

In this study, disruption of boundary layer formation and secondary flow generation were studied. The disruption of boundary layer prevented the flow from becoming fully developed. As a result, the velocity did not become constant along the channel length unlike case 01 . From figure 7 , it can be seen the fluid velocity was variable along the channel for cases $(02,03,04,05)$. Therefore, interconnectors and obstacles disrupted the boundary layer formation as intended.

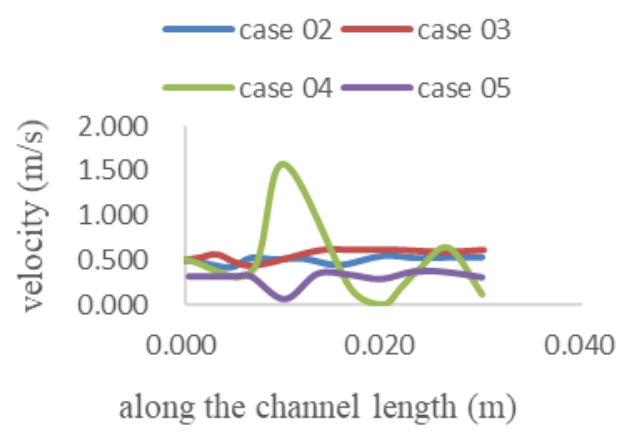

Fig.7. Velocity along channel length for cases (02, 03, 04, 05)

The disruption in boundary layer formation can be observed from figure 8 where the temperature contours are presented. It can be seen from fig. 8 that there are so significant disruption in thermal boundary layer for case 02 and 03 , whereas case 04 and 05 shows noticeable disturbance in thermal boundary layer formation 


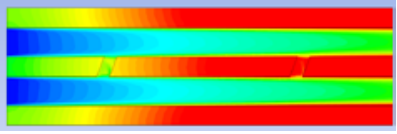

(a)

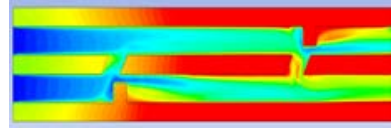

(c)

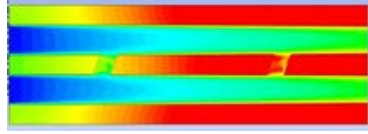

(b)

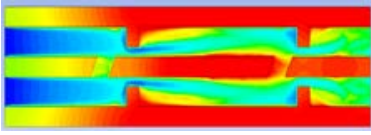

(d)
Fig. 8. Temperature contours for cases $(02,03,04,05)$

In order to further investigate the effects of interconnectors and obstacles, the velocity contours of the modified models are studied. From figure 9 it can be observed that, in cases 04 and 05, there is significant amount of secondary flow through the interconnectors between the channels. However, for both case 02 and 03, almost no secondary flow is visible through the channels.

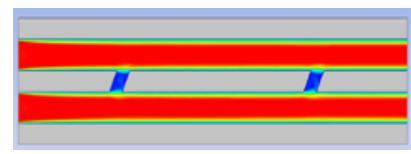

(a)

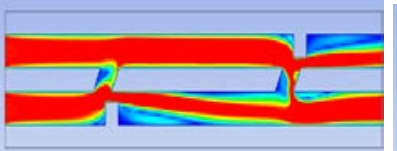

(c)

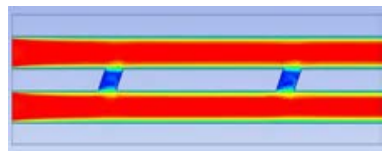

(b)

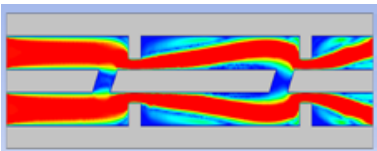

(d)
Fig. 9. Velocity contours for cases $(02,03,04,05)$

The disruption of boundary layer and secondary flow generation decreases the boundary layer thickness, as a result overall thermal resistance decreases which enhances the heat transfer capacity. In figure 10(a) overall thermal resistance of the studied cases are presented as a function of pumping power. It is observed that case 05 has the least overall thermal resistance. Moreover, the main purpose of a heat sink is to dissipate the heat and reduce the temperature of the system. To analyze the thermal performance of the heat sinks, maximum temperature of the heat sinks can be compared which is presented in figure 10(b). The heat sink with least maximum temperature has better heat transfer capacity. It is observed that, among all the cases, case 05 has the least maximum temperature which further satisfies that this model has better heat transfer capacity than rest of the models.
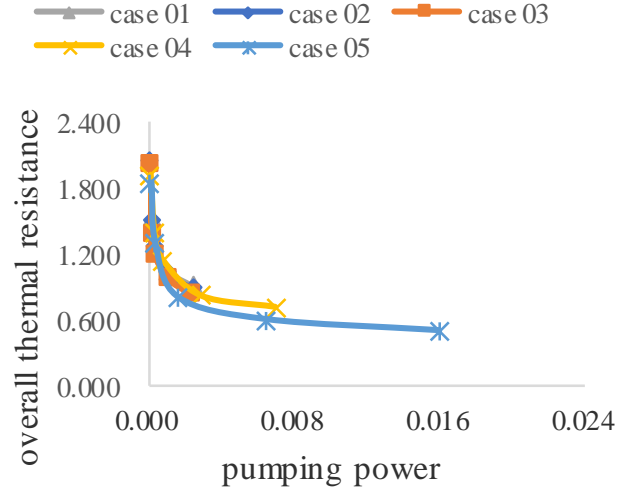

(a)

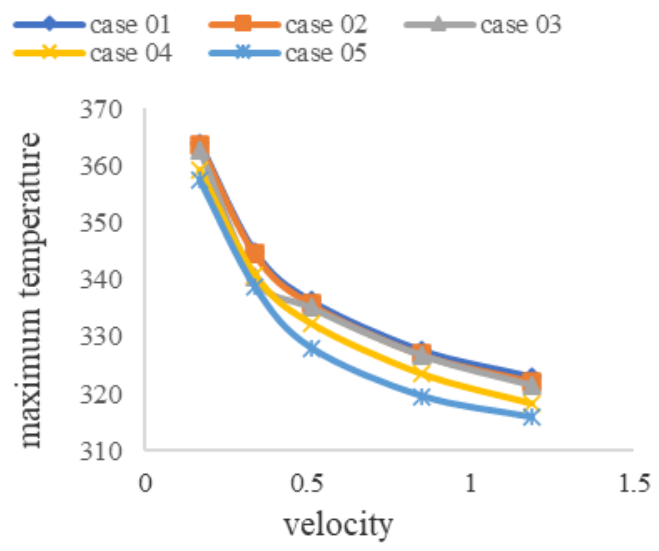

(b)

Fig. 10. (a) Comparison of overall thermal resistance as a function of pumping power

(b) Comparison of maximum temperature as a function of velocity

The increase of Nusselt number with increasing Reynold's number is observed in figure 11. Nusselt number increases for all the five cases. However, among all the cases highest increase of Nusselt number is observed for case 05 .

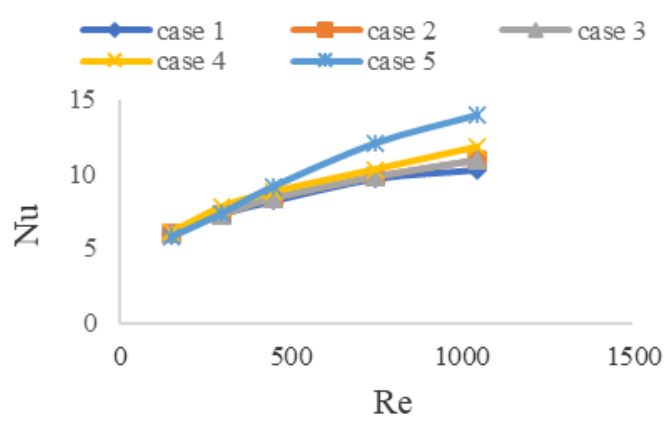

Fig. 11. Comparison of Nusselt number with respect to Reynold's number 


\section{Conclusion}

The purpose of heat sink is to dissipate heat from warm system to cool it down. In this study a numerical analysis of three-dimensional laminar flow through rectangular channel heat sink is studied. The aim was to increase heat transfer rate by disrupting the formation of boundary layer and generating secondary flow between the channels by introducing interconnectors and obstacles at different positions and numbers inside the channel. After analyzing the results, the findings were:

- $\quad$ For case 01 boundary layers started developing along the channel length from inlet of the heat sink to the outlet. As the boundary layers became thicker the heat transfer rate decreased.

- To enhance heat transfer rate, at first only interconnectors were introduced which did not have any significant impact on heat transfer rate.

- Although there was not any notable boundary layer disruption in case 02 and 03, due to having larger interconnector width case 03 showed slightly better performance than case 02 .

- For parallel flow, interconnector alone couldn’t create necessary secondary flow, so obstacles were introduced in case 04 and 05 which showed significantly better performance than previous cases.

At first, we would like to express our deepest gratitude and respect for our thesis supervisor professor Dr. A.K.M. Monjur Morshed, Department of Mechanical Engineering, BUET for the continuous support and encouragement throughout the whole process of the completion of this thesis. He has patiently guided us and helped us in every step of this task.We would also like to thank Debanan Bhadra Dipto, lecturer, Department of Aeronautical Engineering, MIST for his help and support.All our acknowledgments and thanks are expressed to our teachers, classmates and our families who were supportive and encouraged us in our studies.

\section{References}

1. W. H. Hsieh, J. Y. Wu, W. H. Shih and W. C. Chiu, "Experimental investigation of heat-transfer characteristics of aluminum-foam heat sinks," Int. J. Heat Mass Transf. 47, 5149-5157 (2004)

2. D. B. Tuckerman and R. F. W. Pease, "Highperformance heat sinking for VLSI," IEEE ELECTR DEVICE L 2, 126-129 (1981)

3. S. E. Ghasemi, A. A. Ranjbar and M. J. Hosseini, "Experimental and numerical investigation of circular minichannel heat sinks with various hydraulic diameter for electronic cooling application,” MICROELECTRON RELIAB 73, 97105 (2017)

4. M. B. Bowers and I. Mudawar, "High flux boiling in low flow rate, low pressure drop mini-channel and micro-channel heat sinks," Int. J. Heat Mass Transf. 37, 321-332 (1994)
5. N. Lei, A. Ortega and R. Vaidyanathan, "Modeling and optimization of multilayer minichannel heat sinks in single-phase flow," ASME InterPACK Conference 2, 29-43 (2007)

6. T. C. Hung, W. M. Yan and W. P. Li, “Analysis of heat transfer characteristics of double-layered microchannel heat sink,” Int. J. Heat Mass Transf. 55, 3090-3099 (2012)

7. A. Tikadar, S. K. Oudah, T. C. Paul, A. S. Salman, A. K. M. M. Morshed and J. A. Khan, "Parametric study on thermal and hydraulic characteristics of inter-connected parallel and counter flow minichannel heat sink,” Appl. Therm. Eng. 153 (2019)

8. Md. M. Hossain, A. Tikadar, F. Bari and A. K. M. M. Morshed, "Enhanced heat sink with geometry induced wall-jet," AIP Conference Proceedings (2016)

9. A. Tikadar, "Enhancing thermal-hydraulic performance of parallel and counter flow minichannel heat sinks utilizing secondary flow: a numerical and experimental study," Theses and Dissertations 5453, University of South Carolina (2019)

10. M. K. Moraveji and R. M. Ardehali, “CFD modeling (comparing single and two-phase approaches) on thermal performance of $\mathrm{Al}_{2} \mathrm{O}_{3}$ /water nanofluid in mini-channel heat sink,” Int. Commun. Heat Mass Transf. 44, 157-164 (2013) 